\title{
On Influence of Music Education on Emotional Development of Pre-school Children
}

\author{
Lei Liu \\ China West Normal University, China \\ email: liulei58292@126.com
}

Keywords: Music Education; Pre-school children; Emotion; Influence

\begin{abstract}
Music education is an important part of infant education, which belongs to an important means for shaping personality and aesthetics of pre-school children. Music produces a subtle role for children emotional development with unique appeal. It has extremely important role for perfecting infant personality and aesthetic experience. In the paper, influence of music education on emotional development of pre-school children is preliminarily studied.
\end{abstract}

\section{Introduction}

Infant education is an organic integral part of basic education. Kindergarten music education plays an important role in infant education. Music is performance art of sound, which is an external manifestation form of inner emotions. Infant potential can be explored through music education in pre-school stage, thereby shaping their healthy and lively personality, cultivating positive emotional development of infants, and promoting overall development of infants. Therefore, music education is closely linked with pre-school child development, and music education is particularly important especially in emotional development of pre-school children ${ }^{[1]}$. Therefore, what is the link between music education and emotional development of pre-school children? The author analyzes shallowly from the following aspects.

\section{Music and Emotion}

Concept of Emotion. Emotions refer to emotion aspect of emotion, which is only used for humans. We use the concept of 'emotions' during description of people's senior social emotion especially. It refers to certain attitude and experience of people on recognized objective environment and objective matters. It is a direct reflection status of people for reflecting people's values. Although it is invisible and erratic, it is produced with people's recognition activities. Meanwhile, it can be used for promoting or hindering recognition development. People's attitude and experience reflect whether people can be satisfied or not. In general, people can hold positive attitude and produce love, satisfaction and other experience aiming at matters meeting demands. People can hold negative attitude, and produce hate, unsatisfied and unpleasant experience on matters unsatisfying demand ${ }^{[2]}$. Therefore, 'emotions have special subjective experience, significant physical-physiological changes and external expression behaviors. Physical activity (sensory and emotional reactions) and mental activities (emotional activity) are intertwined together in the emotion process. Emotional experience is the starting point of human mental activity, and emotion occupies core position in psychologicalcultural structure.

Human emotions are embodied in direct judgment of likes and dislikes without thinking and forcibility. This is orientation instrument of human understanding and practice activities. Lenin once said: 'pursuit on truth is not available without 'human emotions ${ }^{[3]}$. Therefore, it is one of important tasks to cultivate positive emotions in current education. Preschool children are just at an important stage of personal emotions developed from junior level and senior level progressively. Emotion self-regulation ability is continuously improved with gradual expansion of children social exchange scope, increasingly rich emotion experience and gradually dedicated differentiation. More advanced 
social emotions, such as morality, rational sense and beauty, begin to gradually develop, and their emotions are unstable, short and explosive. Usually, their emotions are expressed through facial expressions, which are impulsive, easily exposed and easily shifted from one face expression to another expression ${ }^{[4-5]}$. The period is one of key stages for emotional development of pre-school children. The children emotion emotions are driving force status of children behavior mode. Children development is inextricably linked with cognitive development and personality development. Therefore, educators should focus on training and educing children positive emotions according to psychological and physiological development characteristics of children ${ }^{[6]}$.

Effect of Music on Emotion Development. Music is the most emotional art, which is one of the oldest art forms for mankind. It accompanies development of human history with its unique artistic charm, thereby meeting demand of human spiritual needs. It exists by virtue of acoustic vibration. It is art of various emotion reactions and emotional experience which is embodied in time and caused through human auditory organ ${ }^{[7]}$. It can move human mind with sincere, vivid and deep emotion. Music is the art of expressing emotion by sound. It has the most important feature of moving people with love and emotion. Musician Stravinsky said: 'Music is emotion, and there is no music without emotion. Music movement mode has isomorphism relationship with human emotion movement mode. Therefore people can easily master emotion connotations matched by music. In music, auditory sense is directly activated through organized sound. It is means of expressing human emotions through vocal variety, relaxed and changed rhythm, efforts with clear lines, floating progress, exciting speed, colorful timbre, etc. It can just generalize physical properties of emotion mental activities: speed, strength, movement, thereby resulting in a special and extraordinary resonance. It has strong emotional effect on human emotion. Therefore, music education is one of effective means to promote children emotional development.

\section{Domestic and Foreign Famous Music Education Thought}

Music is the soul of children life. Mr. Chen Heqin, famous educator, has the following music education thought: 'music is the soul of the children life'. He said: music has real value that we contact with music, rhythm beauty achieves physical and mental resonate and common sense; people feel the harmony by reconcile beauty for developing unity. Therefore, we should penetrate into children life by music vitality and interests. Children can be uniformly consciously during work, play or labor, thereby achieving performance with consistent behavior and cheerful spirit, and making children life full of music. It is visible that music education and children emotion development are emphasized according to music education thought of Mr. Chen Heqin. He believes that 'music is used for improving children will, cultivating children sentiment, enriching children emotion, making children show themselves truly, and guiding children to creative development in music education.' Music education of pre-school children should be based on training appreciation and experience of children. Children can play in study and study in play, thereby enhancing their ability to feel beauty and create beauty, and promoting emotional development.

Experiencing Music and Experiencing Emotion. Dalcroze (Enile Jaques Ddcroze), Swiss educator, proposed the famous doctrine of 'Body Rhythm'. He believes that 'music education has the fundamental purpose of aesthetic emotion education, and music has the essence of people's reflection on emotion'. 'Experience of music and experience of emotion' are the purpose of Dalcroze's music education reform. His 'body rhythm theory' lies that children can arouse human music instinct during acceptance of music education core is to allow children to accept music education process physically and psychologically at the same time through rhythmic movement combining music and body. Own emotions and feelings can be experienced and expressed through muscle tension and relaxation sense $^{[8]}$. Inner emotion is expressed in external world through gestures and various body actions, thereby children can actually experience shocking force and provoked emotions brought by music works. 


\section{Music Education and Pre-school Children Emotional Development}

Pre-school children music education is education practical activity with music as content, which is conducted through singing, rhythm, music games, music appreciation, playing musical instruments and other musical practical activities. Infants can learn and master several most preliminary musical knowledge and skills in various music practical activities, thereby developing creativity. Music education plays an extremely important role for children development. It expresses the most delicate mental activity and emotional volatility of human beings through melody, audio and other means. Music not only can assist children to clearly establish own emotion, but also can make children to communicate with own emotion. Meanwhile, children also can communicate with emotion of other people. A good music work and a successful music education activity can make children produce emotional resonance on music. Therefore, excellent mood and emotion of children can be trained. In addition, children can widely contact works expressing different emotions, different contents and different styles in music education. Therefore, emotion world of children also can be gradually enriched ${ }^{[9]}$.

The Ministry of Education issued 'Full-time Education Music Curriculum Standards (trial version)' in July 2001. Emotions, attitudes and values are regarded as important parts in course purpose. The standard clearly states that: music education should be mainly based on aesthetics. When children experience beauty and feel beauty in music learning, their positive emotion development can be driven. Music education, one of art educations in kindergarten, also follows the principle. We should cultivate music aesthetic ability of children, develop children's aesthetic sensibility, promote positive emotional development of children, shape perfect personality of infants, and prepare for comprehensive development of pre-school children ${ }^{[10]}$. Emotion of pre-school children is developed from lower level to higher level and from instability to stability. They contact with a wide variety of excellent music works, participate in various colorful musical activities, and learn a variety of simple musical skills. Their emotions are gradually enriched. They will gradually comprehend love, beauty, kindness , etc. Meanwhile, they will hate evil, ugly, etc. In addition, body growth and development of pre-school children will also be promoted. Therefore, we should guide infants to contact excellent and healthy music works in music education, and guide children to feel thinking and emotion of works, thereby producing resonance and beauty, improving children's artistic taste, and promoting advanced social-emotional development of infants.

\section{Music Education Thinking of Pre-school Children}

Children naturally love music, and love of music is nature for children. They can experience happiness in music activities, thereby children can be satisfied. We conduct music education on pre-school children mainly through two approaches: one is school music education; the other is family music education. The whole society pays more and more attention to education issue of pre-school children with society progress and improvement of people's material living standards. We should pay more attention to music education of pre-school children in order to cultivate comprehensive development talents required by the society. 'Approach of music education' is the issue worthy of attention and thought from music educators. Currently, more and more parents would like to spend expensive cost and allow their children to learn singing, playing piano, dancing, etc. Many schools successively set up some art training classes, therefore massive 'piano talents', and 'little singers'... are produced. Whether infants enjoy the process or not, whether they actually like the process or not, and whether children can accept the music education mode suitably or not are problems that should be thought by people.

We should always remember the follows for both school music education and family music education: music is only a means, which aims at educating and cultivating talents. Music education does not focus on 'teaching' but for awakening and inducing out potential of every person. Music teaching of pre-school children not just includes teaching children to sing, dance and play piano, music ability training of children does not aim at pursuing early music skill training and training little 
singer, little dancer and little performers. It aims at opening a window of music world for children. Therefore they can be developed more comprehensively. Our pre-school music education is shown as follows: domestic and foreign advanced educational concepts is utilized for educating children according to pre-school children's physical and psychological development rules and characteristics. Many children who will not be musicians in the future are considered, they are encouraged and assisted for loving music and enjoying music, thereby subtly cultivating sentiment of children, enriching emotion of children, allowing children to grow healthily and happily, and comprehensively developing new generation.

\section{Conclusion}

In summary, music is the most emotional art. Pre-school children music education should be based on aesthetics. Positive emotions of children are cultivated. Subjectivity of children should be exerted in music education teaching activity. Parents and teachers should be guiders for children during music learning rather than dominators. We should always consider that children is the center of learning. Music education can exert effect and function thereof according to the principle, thereby achieving actual purpose of music education. Music educators should clearly recognize that we should cultivate children's feeling of beauty in music, promote emotional development of children, and strengthen artistic education, therefore children can grow healthily into people with comprehensive development.

\section{References}

[1] Yao Chen. Study of Music Teaching Gamification in Kindergarten, J. Hunan Normal University. 2014,5 (3): 42-47.

[2] Xu Wenjuan. On Importance of Music Education for Pre-school Children Development, J. Music Concept. 2014,8 (2): 15-22.

[3] Tang Fang. Study of Potential Influence of Permeable Music Activities on Pre-school Children Comprehensive Development , J. Hebei Normal University. 2008,3 (33): 51-63.

[4] Zheng Yuxiang. Value of Music Education on Pre-school Children Development , J. Hebei University. 2004,12 (25): 23-29.

[5] Li Ying. Emotional Context of Early Music Education- Revelation of Wang Donghua Mother Education on Early Music Education , J. China Conservatory College. 2012, 4 (14): 56-60.

[6] Chen Chong. Study of Classical Music and Infant Life Education , J. Hunan Normal University. 2012,05 (4): 29-40.

[7] Ji Huijuan. On Influence Approach of Music Education on Pre-school Children Aesthetic Education , J. Chinese Out-of-school Education. 2012,5 (1): 15-19.

[8] Zhang Liang. Influence of Music Education on Children Growth , J. Success (Education). 2012,3 (2): $34-41$.

[9] Lu Lin. On Study of Preschool Music Education on Children Development Value , J. Xianning College Journal. 2012,7 (8): 36-42.

[10] Tang Fang. Osmotic music activity to learn the latent influence research that the develops completely of preschool child. Shijiazhuang: Hebei Normal University, 2008. 